\title{
Seasonal Predictability over Europe Arising from El Niño and Stratospheric Variability in the MPI-ESM Seasonal Prediction System
}

\author{
Daniela I. V. Domeisen, ${ }^{*}$ Amy H. Butler, ${ }^{+}$Kristina FrÖHlich, ${ }^{\#}$ Matthias Bittner, ${ }^{@}$ \\ WOlfGang A. MÜLler, ${ }^{\&}$ AND JOHANNA BAEHR* \\ * Institute of Oceanography, Center for Earth System Research and Sustainability (CEN), Universität Hamburg, \\ Hamburg, Germany \\ ${ }^{+}$Cooperative Institute for Research in Environmental Sciences, and NOAA/Earth System Research \\ Laboratory/Chemical Sciences Division, Boulder, Colorado

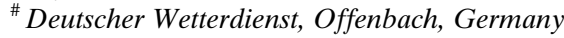 \\ ${ }^{\circledR}$ International Max Planck Research School on Earth System Modeling, Max Planck Institute for \\ Meteorology, Hamburg, Germany \\ \& Max Planck Institute for Meteorology, Hamburg, Germany
}

(Manuscript received 17 March 2014, in final form 27 September 2014)

\begin{abstract}
Predictability on seasonal time scales over the North Atlantic-Europe region is assessed using a seasonal prediction system based on an initialized version of the Max Planck Institute Earth System Model (MPIESM). For this region, two of the dominant predictors on seasonal time scales are El Niño-Southern Oscillation (ENSO) and sudden stratospheric warming (SSW) events. Multiple studies have shown a potential for improved North Atlantic predictability for either predictor. Their respective influences are however difficult to disentangle, since the stratosphere is itself impacted by ENSO. Both El Niño and SSW events correspond to a negative signature of the North Atlantic Oscillation (NAO), which has a major influence on European weather.

This study explores the impact on Europe by separating the stratospheric pathway of the El Niño teleconnection. In the seasonal prediction system, the evolution of El Niño events is well captured for lead times of up to 6 months, and stratospheric variability is reproduced with a realistic frequency of SSW events. The model reproduces the El Niño teleconnection through the stratosphere, involving a deepened Aleutian low connected to a warm anomaly in the northern winter stratosphere. The stratospheric anomaly signal then propagates downward into the troposphere through the winter season. Predictability of 500-hPa geopotential height over Europe at lead times of up to 4 months is shown to be increased only for El Niño events that exhibit SSW events, and it is shown that the characteristic negative NAO signal is only obtained for winters also containing major SSW events for both the model and the reanalysis data.
\end{abstract}

\section{Introduction}

Seasonal predictability over Europe is limited compared to the tropics due to the smaller number of predictors for European weather that exhibit variability on seasonal time scales, and the smaller role of persistence on these time scales. While El Niño-Southern Oscillation (ENSO), the quasi-periodic variation of tropical Pacific surface temperatures, has teleconnections influencing regions around the globe, it exhibits only a weak

Corresponding author address: Daniela Domeisen, Institute of Oceanography, Universität Hamburg, Bundesstrasse 53, 20144 Hamburg, Germany.

E-mail: daniela.domeisen@zmaw.de signature over Europe (Brönnimann 2007). However, ENSO is nevertheless one of the strongest predictors on seasonal time scales for the North Atlantic-European region (Brönnimann 2007; Scaife and Knight 2008).

Another suggested source of predictability on seasonal time scales over the Northern Hemisphere mid and high latitudes arises from stratospheric influence in the form of sudden stratospheric warming (SSW) events (Sigmond et al. 2013; Mukougawa et al. 2009). SSW events are characterized by a breakdown of the stratospheric polar vortex and a warming of the polar stratosphere. Predictability arising from these events is limited by the timing of their occurrence to the boreal winter-spring season. While predicting specific SSW events at lead times of more than 2 weeks has proved difficult (Gerber 
et al. 2009; Marshall and Scaife 2010), once strong SSW events occur they can influence the winter stratosphere for several weeks and are associated with a relative warming in the polar lower stratosphere. Because of the long radiative time scales in the lower stratosphere, the anomalous temperature signal can persist there up to several weeks, where the anomaly persists particularly long for so-called polar-night jet oscillation events (Hitchcock et al. 2013). This continuous forcing of the tropopause can lead to a strong impact on the extratropical tropospheric circulation and surface climate (Baldwin and Dunkerton 2001; Thompson et al. 2002) and is suggested to add predictability on seasonal time scales over the Northern Hemisphere extratropics (Sigmond et al. 2013).

While predictability over Europe can be affected by stratospheric variability (Butler et al. 2014), the stratosphere is not an independent predictor; rather, the stratosphere is itself influenced by tropospheric variability. Tropical Pacific variability in the form of ENSO is thought to affect the seasonal evolution of the wintertime stratosphere (Quiroz 1983; van Loon and Labitzke 1987; Fraedrich and Müller 1992), which has been more recently discussed in Manzini et al. (2006), Cagnazzo and Manzini (2009), Ineson and Scaife (2009), and Garfinkel and Hartmann $(2007,2008)$, as well as the frequency of SSW events (Bell et al. 2009; Butler and Polvani 2011). Although both the warm (El Niño) and cold (La Niña) phases of ENSO can influence stratospheric variability, we focus here on El Niño, which generally has stronger impacts on the seasonal-mean state of the stratosphere (Manzini et al. 2006; Garfinkel and Hartmann 2008; Free and Seidel 2009).

Multiple studies have suggested a potential for improved predictability for either predictor-that is, SSW events (Baldwin and Dunkerton 2001; Sigmond et al. 2013) and ENSO (e.g., Li and Lau 2013) — based on dynamical links and correlation, and both El Niño and SSW events tend to be associated with a negative winter/spring NAO response over the North Atlantic-Europe region. Since they are shown to not be independent, and given the resulting difficulty in determining the role of the stratosphere in seasonal predictability over Europe, this study aims to disentangle the importance of the stratospheric pathway of the ENSO impact on Europe by employing a global seasonal prediction system. For this purpose, predictability of both El Niño and the stratosphere, as well as the physical mechanism in terms of teleconnections between the tropical Pacific and the winter stratosphere, is investigated. While several ENSO teleconnections may influence Europe (e.g., Toniazzo and Scaife 2006; Brönnimann 2007; Graf and Zanchettin 2012; Li and Lau 2013), Butler et al. (2014) suggested in a recent study that the stratospheric pathway is key to predictability from ENSO over Europe. We will therefore focus on the importance of the stratospheric pathway for capturing the ENSO signal over Europe.

The analysis is performed using a seasonal prediction system in order to evaluate the dynamical coupling between the tropical Pacific, the extratropical stratosphere, and the North Atlantic-Europe region, and to assess how the stratosphere contributes to communicating the ENSO signal, as well as to evaluate potential predictive skill over Europe. The prediction system is based on a coupled climate model initialized from reanalysis data.

ENSO teleconnections are an important test for seasonal prediction systems, since these are some of the strongest events that are predictable on seasonal time scales and that also exhibit teleconnections around the globe. As seasonal prediction systems improve and are used operationally, it is important to evaluate their performance with respect to the most important teleconnections that influence predictability over Europe. Studies comparing the representation of these teleconnections between different models are currently underway.

A brief description of the model will be given in section 2. Since a reliable prediction of the evolution of $\mathrm{El}$ Niño events is crucial for our goal to utilize the teleconnections of tropical Pacific variability across the globe, and in particular to assess the impact on the North Atlantic-Europe region, section $3 a$ will give a brief overview of the predictability of El Niño in our model. The model performance for the stratosphere is assessed in section 3b. The influence of El Niño on the stratosphere is described for the model and compared to reanalysis data in section 3c. Section 3d explores stratospheric influence on the troposphere, and section $3 \mathrm{e}$ investigates the importance of stratospheric variability for the prediction of European weather for both El Niño and the stratospheric pathway of El Niño. Sections 4 and 5 provide a discussion and conclusions.

\section{Methods}

\section{a. Model setup}

The seasonal prediction system employed here is based on the global Max Planck Institute (MPI) Earth System Model at low vertical resolution (MPI-ESM-LR) as used for the Coupled Model Intercomparison Project phase 5 (CMIP5; Taylor et al. 2012) simulations. The atmosphere consists of the ECHAM6 model (Stevens et al. 2013) at T63L47 resolution, which corresponds to a horizontal resolution of about $200 \mathrm{~km}\left(1.875^{\circ}\right)$ and 47 vertical levels with a top level at $0.01 \mathrm{hPa}(80 \mathrm{~km})$. The atmosphere is coupled to the MPI Ocean Model (MPI-OM; Jungclaus 
et al. 2013) at a resolution of GR15L40 (1.5 horizontal resolution in the tropics, 40 vertical levels), and to a land model including a hydrological discharge model and an interactive sea ice model. For a detailed description of the model, the performed model runs, and the evaluation of the model skill, see Baehr et al. (2014).

A nudged experiment is first performed that is nudged by Newtonian relaxation toward reanalysis data. For nudging in the atmosphere, the Interim European Centre for Medium-Range Weather Forecasts (ECMWF) Re-Analysis (ERA-Interim; Dee et al. 2011) is used with a relaxation time scale of 1 day. In the ocean, the ECMWF Ocean Reanalysis System 4 (ORA-S4; Balmaseda et al. 2013 ) is used with a relaxation time scale of 10 days, and for sea ice the observational National Snow and Ice Data Center (NSIDC) sea ice concentration data (Fetterer et al. 2002) are employed with an effective relaxation time scale of 20 days (Tietsche et al. 2013). From the nudged model experiment, nine ensemble members are started on 1 November of each year between 1980 and 2011 with a duration of one year each, using the breeding method for ensemble generation (Baehr and Piontek 2014). The first month after the initialization (i.e., November) is discarded because of the possibility of initialization shock.

\section{b. Data}

The model results in this study are compared to ERA-Interim reanalysis data. Although the model atmosphere is initialized from ERA-Interim data, the extratropical stratosphere does not retain the memory of the initial conditions for longer than about 2 weeks. Any predictable part of the stratospheric influence on the extratropical troposphere during the winter season can therefore be considered to arise from long-lived forcings such as ENSO, rather than from extratropical stratospheric initial conditions in November. We consider December-March (DJFM) seasonal averages for assessing the influence of both El Niño and SSW events.

The ENSO classification (Table 1) is based on the DJF season of the oceanic Niño index as defined by the Climate Prediction Center [defined by a threshold of $\pm 0.5^{\circ} \mathrm{C}$ for the oceanic Niño index for a 3-month running mean of sea surface temperature anomalies in the Niño-3.4 region $\left(5^{\circ} \mathrm{N}-5^{\circ} \mathrm{S}, 120^{\circ} \mathrm{W}-170^{\circ} \mathrm{W}\right)$, based on centered 30 -yr base periods updated every 5 years]. The analysis period (30 years between 1981 and 2011) contains 10 El Niño, 11 La Niña, and 9 ENSO neutral years (see Table 1). The ENSO phase defined for observations can also be used in this study as the ENSO phase for the model data due to the short lead times considered.
TABLE 1. ENSO phase, volcanic influence, the number of SSW events (for the DJF season) in the model prediction, and the dates of SSW events (for the DJF season) for ERA-Interim for all considered winter seasons. The ENSO classification and SSW criterion are described in section 2. For the model, the number of SSW events for the DJF season is given by the number of events averaged over all ensemble members. Asterisks indicate volcanic eruptions: El Chichón (March-April 1982) and Mt. Pinatubo (June 1991).

\begin{tabular}{|c|c|c|c|}
\hline Winter season & ENSO phase & $\begin{array}{c}\text { No. of SSW } \\
\text { events (model) }\end{array}$ & $\begin{array}{c}\text { SSW dates } \\
\text { (ERA-Interim) }\end{array}$ \\
\hline $1981 / 82$ & Neutral & 0.33 & $4 \mathrm{Dec}$ \\
\hline $1982 / 83$ & El Niño* & 1.00 & - \\
\hline $1983 / 84$ & La Niña & 0.78 & $24 \mathrm{Feb}$ \\
\hline $1984 / 85$ & La Niña & 0.11 & $31 \mathrm{Dec}$ \\
\hline $1985 / 86$ & Neutral & 0.22 & - \\
\hline $1986 / 87$ & El Niño & 0.89 & 23 Jan \\
\hline $1987 / 88$ & El Niño & 0.67 & $7 \mathrm{Dec}$ \\
\hline $1988 / 89$ & La Niña & 0.33 & $21 \mathrm{Feb}$ \\
\hline $1989 / 90$ & Neutral & 0.33 & - \\
\hline 1990/91 & Neutral & 0.44 & - \\
\hline $1991 / 92$ & El Niño* & 0.78 & - \\
\hline $1992 / 93$ & Neutral & 0.44 & - \\
\hline $1993 / 94$ & Neutral & 0.78 & - \\
\hline $1994 / 95$ & El Niño & 0.56 & - \\
\hline $1995 / 96$ & La Niña & 0.44 & - \\
\hline $1996 / 97$ & Neutral & 0.78 & - \\
\hline $1997 / 98$ & El Niño & 0.89 & - \\
\hline $1998 / 99$ & La Niña & 0.56 & $15 \mathrm{Dec}, 26 \mathrm{Feb}$ \\
\hline $1999 / 2000$ & La Niña & 0.22 & - \\
\hline $2000 / 01$ & La Niña & 0.56 & $11 \mathrm{Feb}$ \\
\hline $2001 / 02$ & Neutral & 0.78 & $30 \mathrm{Dec}, 17 \mathrm{Feb}$ \\
\hline $2002 / 03$ & El Niño & 0.44 & $18 \mathrm{Jan}$ \\
\hline $2003 / 04$ & Neutral & 0.22 & 4 Jan \\
\hline $2004 / 05$ & El Niño & 0.33 & - \\
\hline $2005 / 06$ & La Niña & 0.89 & $21 \mathrm{Jan}$ \\
\hline $2006 / 07$ & El Niño & 0.56 & $24 \mathrm{Feb}$ \\
\hline $2007 / 08$ & La Niña & 0.56 & $22 \mathrm{Feb}$ \\
\hline $2008 / 09$ & La Niña & 0.44 & $24 \mathrm{Jan}$ \\
\hline $2009 / 10$ & El Niño & 0.22 & $8 \mathrm{Feb}$ \\
\hline $2010 / 11$ & La Niña & 0.22 & - \\
\hline
\end{tabular}

The SSW events are defined by a threshold of a zonal mean zonal wind reversal to easterlies at $60^{\circ} \mathrm{N}$ and $10 \mathrm{hPa}$ with a minimum interval of 20 days between events (following Charlton and Polvani 2007) during the months of December-February; that is, the central date of the SSW event is the day when the wind first switches from westerly to easterly. No additional constraints on the number of days with westerly winds between events have been used. These events, here defined from ERA-Interim data, are consistent with the dates listed in Charlton and Polvani (2007) for 40-yr ECMWF Re-Analysis (ERA-40; Uppala et al. 2005) data for the overlap period (1981-2002). This definition yields 142 SSW events summed over all model ensemble members (57 in El Niño years, 46 in La Niña years, and 39 in neutral years), and $18 \mathrm{SSW}$ events in the reanalysis ( 5 in 

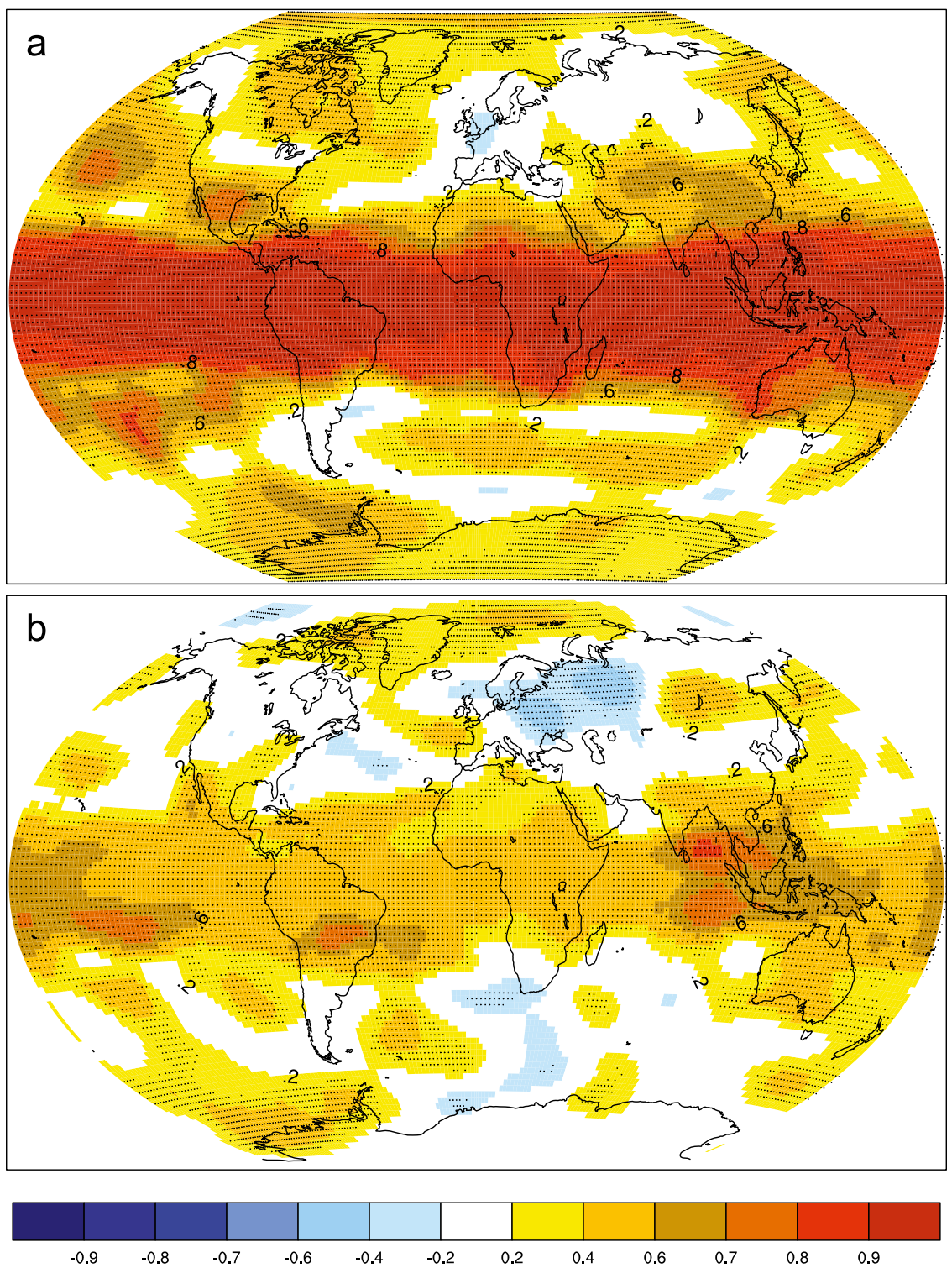

FIG. 1. (a) Anomaly correlation coefficient for $500-\mathrm{hPa}$ geopotential height for DJFM comparing the model prediction to ERA-Interim and (b) persistence skill computed from the anomaly correlation between November and JFM 500-hPa geopotential height in ERAInterim for all winters.

El Niño years, 9 in La Niña years, and 4 in neutral years); see the events listed in Table 1.

\section{Results}

\section{a. Assessment of the model prediction skill}

As a first step, the model's global predictive skill is assessed in terms of the anomaly correlation coefficient (ACC) (Fig. 1a) for geopotential height at $500 \mathrm{hPa}$, based on a comparison to ERA-Interim reanalysis data for the entire globe for the winter mean (DJFM) - that is, for forecast lead times of $1-4$ months. The ACC is defined as

$$
\mathrm{ACC}=\frac{\overline{\left(f-c_{f}\right)\left(a-c_{a}\right)}}{\sqrt{\overline{\left(f-c_{f}\right)^{2}} \overline{\left(a-c_{a}\right)^{2}}}},
$$

where $f$ is the model forecast, $a$ is the reanalysis, and $c_{f}$ and $c_{a}$ are the climatologies of the respective data (following the definitions given by the ECMWF). No bias correction has been applied to the model data. Values of the ACC close to 1 denote areas of high 
a) model prediction
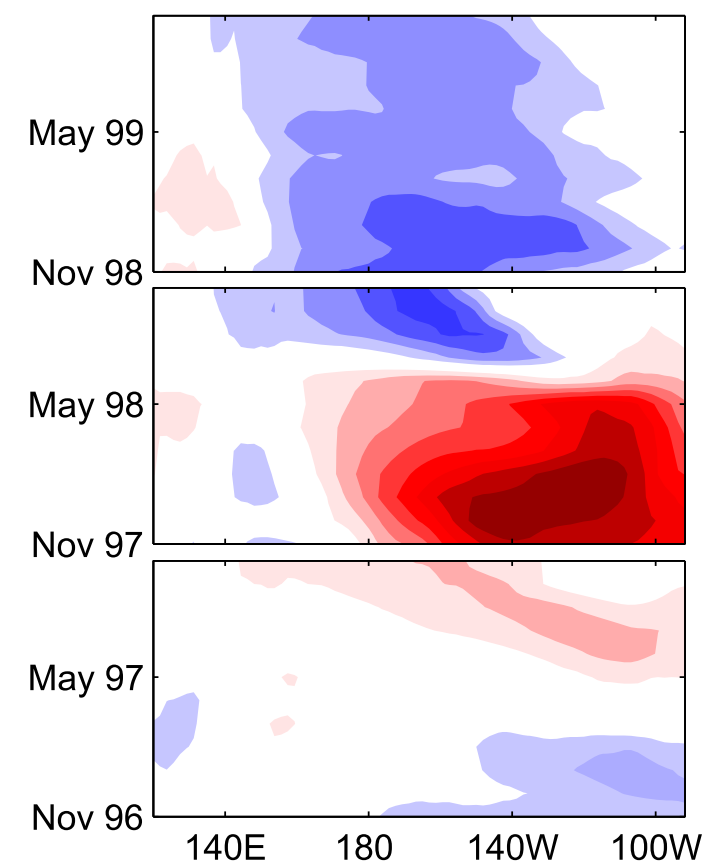

b) ERA-interim
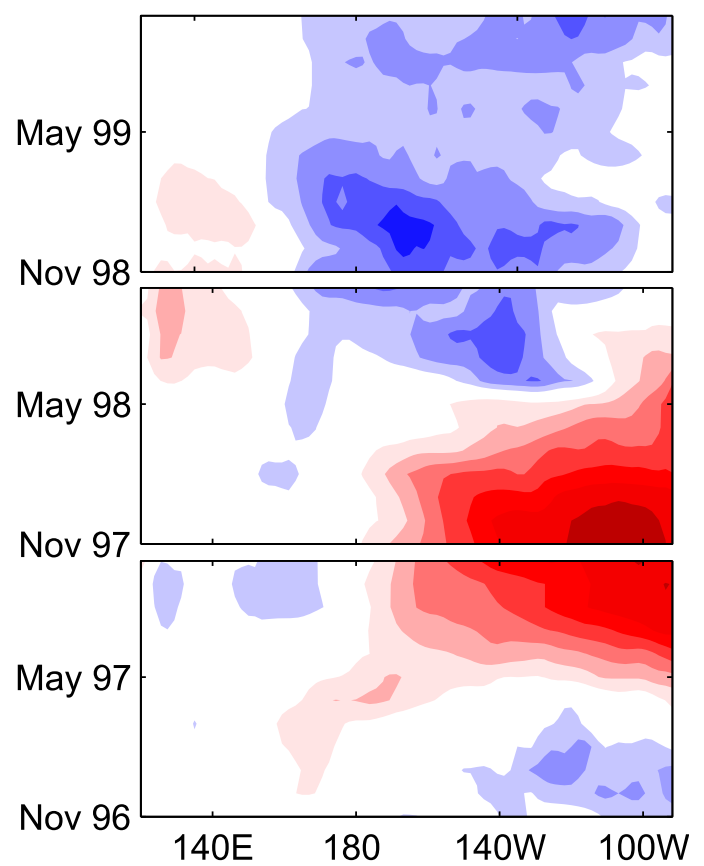

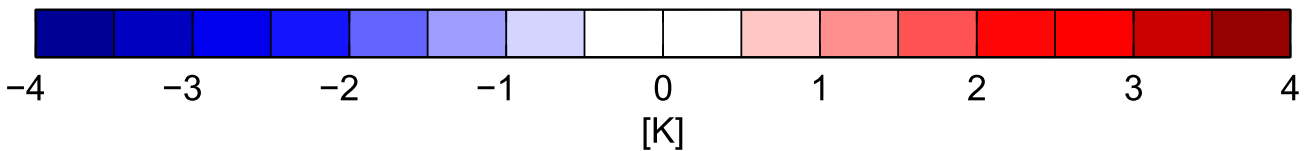

FIG. 2. Hovmöller diagrams of the surface temperature anomaly evolution (K) for the tropical Pacific (averaged between $5^{\circ} \mathrm{S}$ and $5^{\circ} \mathrm{N}$ ) during the strong El Niño event of $1997 / 98$ for (a) the model ensemble mean and (b) ERAInterim reanalysis data. The zero contour has been omitted for clarity. The contour interval is $0.5 \mathrm{~K}$.

predictability, while values close to zero denote areas of no predictability.

Predictability is considerably higher in the tropics as compared to the midlatitudes. A part of this predictability arises from a higher persistence in the tropics, as indicated by Fig. 1b showing the skill of persistence [i.e., the anomaly correlation of 500-hPa geopotential height between November and December-February (DJF)]. These patterns do not qualitatively change for using the anomaly correlation between October and DJFM. In addition, predictability at these lead times during the winter season arises in large part from ENSO, as is indicated by the improved predictability, for instance in the North Pacific, over the southern United States-Caribbean region, and in the Indian Ocean, where there exist well-known ENSO teleconnections (e.g. van Loon and Madden 1981). Subtropical ocean basins are well predicted, whereas extratropical land areas tend to be especially difficult to predict, indicating that Europe represents a challenge for seasonal prediction. It will be shown in the remainder of this study how the improvement in seasonal predictability due to ENSO and its teleconnections may be used to help predict tropospheric climate in the North Atlantic-Europe region.

Overall, the model yields a good prediction of tropical Pacific surface temperature for lead times of up to 6 months when initialized in November (Baehr et al. 2014). As an illustration of the model skill for predicting ENSO, Fig. 2 shows the prediction of the 1997/98 El Niño event in a comparison of surface temperature between the model and ERA-Interim reanalysis for this particularly strong El Niño event. The time evolution of the warm and cold anomalies within the Niño-3.4 region is fairly well reproduced in the model for the first 5-6 months after initialization in November. However, there is a westward bias of the maximum temperature anomaly (a common error in GCMs and seasonal forecast models alike; see, e.g., Luo et al. 2005; Arribas et al. 2011) and a slight overestimation of the magnitude; after about 6 months, predictability decreases (e.g., the strong warming starting in May 1997 is not reproduced in the model). By invoking additional start dates, additional predictability can be gained (not shown), but since this study will concentrate 


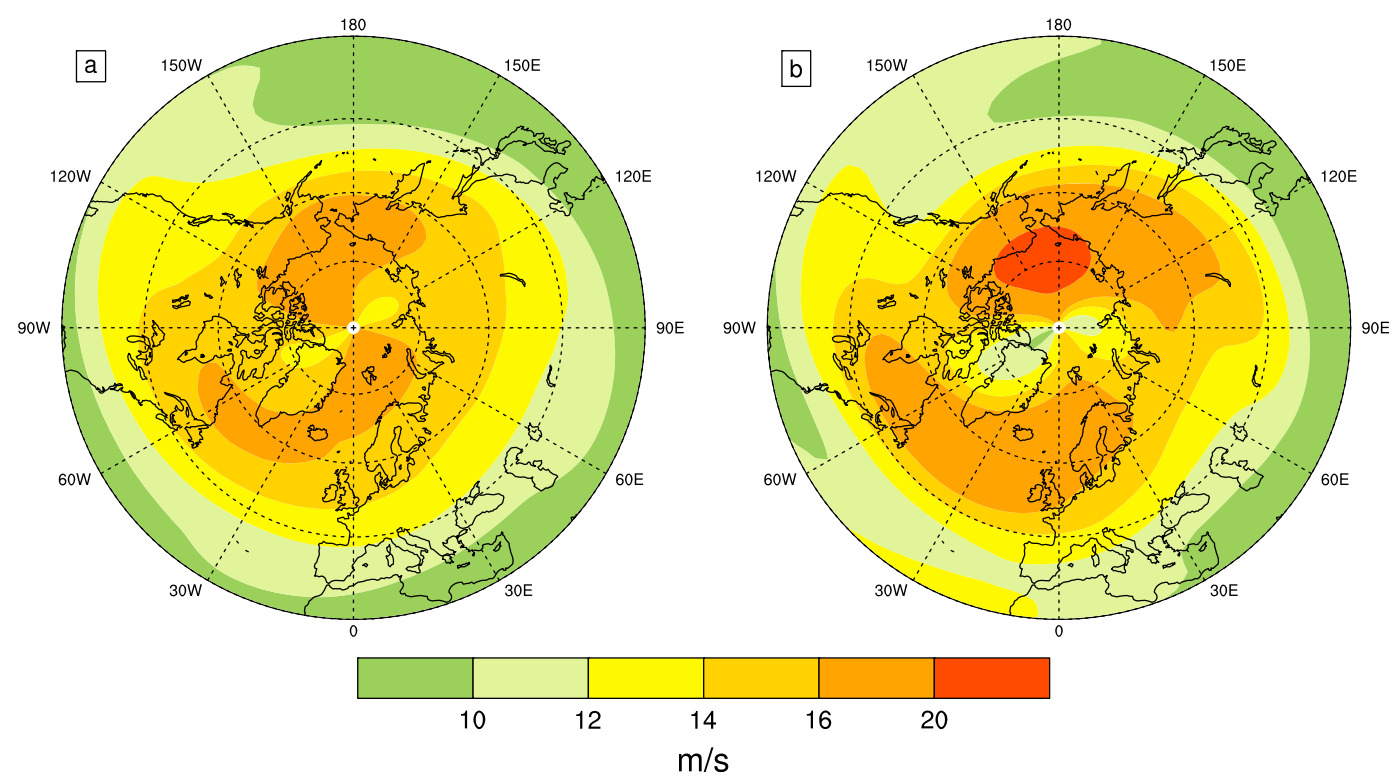

FIG. 3. Variance of the zonal wind $\left(\mathrm{m} \mathrm{s}^{-1}\right.$ ) at $10 \mathrm{hPa}$ for DJF for 1982-2010 for (a) the model predictions (i.e., the average of the variance of the individual ensemble members) and (b) ERA-Interim reanalysis data.

on the winter season, all predictability measures assessed remain within 6 months of the November initialization.

\section{b. Representation of the stratosphere in the model}

Stratospheric winter variability is inherently unpredictable beyond lead times of about 2 weeks; in other words, it is not possible to predict a particular SSW event occurring within the months of December-February from the ensemble start dates in November. In particular cases, during strong tropospheric forcing the stratosphere may exhibit longer predictive time scales (Polvani and Waugh 2004) when considering the integrated upward heat flux over several weeks. In general, however, the evolution of the Northern Hemisphere stratospheric winds exhibits strong inter- and intra-annual variability. Model performance in the stratosphere can instead be assessed by analyzing stratospheric variability and its interannual variation with respect to external forcing such as ENSO.

Stratospheric variability is well represented in the model, with the variability of the individual ensemble members capturing the winter variability in the reanalysis (Fig. 3). The spatial distribution of the variance of DJF zonal wind at $10 \mathrm{hPa}$ exhibits a high consistency between the model ensemble members and the reanalysis data. Higher variability occurs close to the pole, with decreasing values toward lower latitudes, comparable to, for instance, Scaife and James (2000, their Fig. 9). In addition, the preferred wave breaking pattern is reproduced in the model, with higher variability over the North Atlantic and the Arctic Ocean north of the stratospheric
Aleutian high, which often dominates stratospheric winter variability.

SSW frequency in the model is similar to that in the reanalysis, with the reanalysis exhibiting an average frequency of 0.6 events per year for the definition of a wind reversal at $60^{\circ} \mathrm{N}$ and $10 \mathrm{hPa}$ in DJF (cf. Charlton and Polvani 2007), as defined in section 2 and listed in Table 1, while the model exhibits a frequency of 0.53 events per year (averaged over all ensemble members) for the same criterion applied to DJF of all winters (Table 1).

\section{c. ENSO influence on the stratosphere}

The performance of the model in predicting the stratosphere can also be assessed through its ability to simulate the expected teleconnection patterns involving the stratosphere. A suggested pathway of the El Niño signal over Europe passes through the stratosphere. This pathway involves an ENSO teleconnection in the North Pacific (Manzini et al. 2006; García-Herrera et al. 2006). It is hypothesized that the tropical Pacific ENSO anomaly, through anomalous Rossby wave propagation (Horel and Wallace 1981), may influence the climatological extratropical planetary wave pattern (Trenberth et al. 1998) and enhance it through linear interference (Smith et al. 2010; Fletcher and Kushner 2011). This is suggested to drive the amplification of the waves during El Niño and ultimately weaken the vortex (Garfinkel and Hartmann 2008).

Examining this pathway in the model, we find that the pressure anomaly due to El Niño in the northern Pacific 

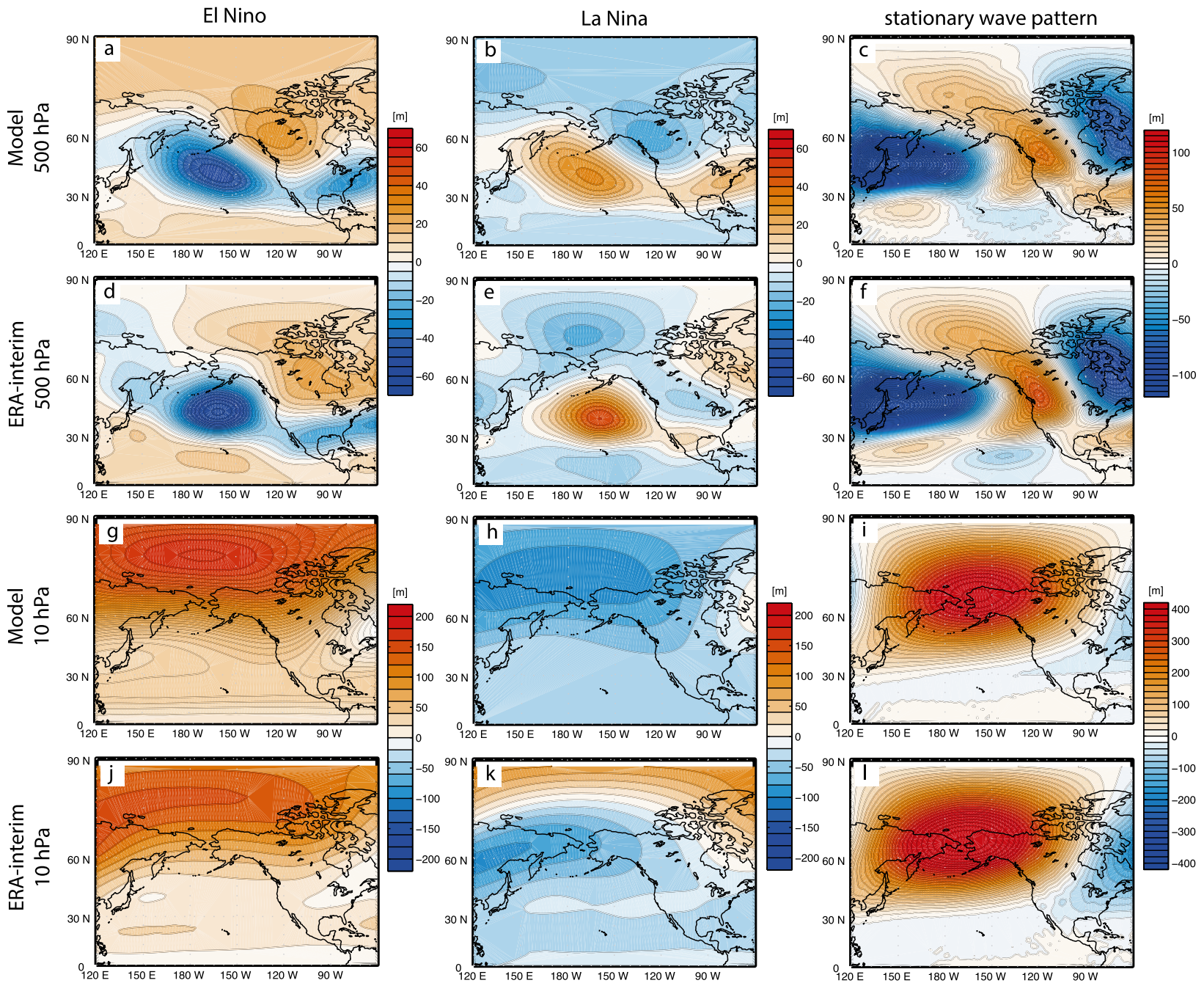

FIG. 4. Geopotential height anomaly composite (m) at (a)-(f) $500 \mathrm{hPa}$ and (g)-(l) $10 \mathrm{hPa}$ in the North Pacific region averaged over DJF for (left) El Niño (10 events) and (center) La Niña events, and (right) for the climatological stationary wave pattern, that is, climatology with the zonal mean removed, for (a)-(c),(g)-(i) the model ensemble and (d)-(f),(j)-(l) ERA-Interim reanalysis data. Contour interval: $5 \mathrm{~m}$ at $500 \mathrm{hPa}$ in (a)-(f), $20 \mathrm{~m}$ at $10 \mathrm{hPa}$ in (g)-(l).The numbers on the color scales run from 60 to -60 for (a), (b), (d), and (e), and from 100 to -100 for (c) and (f). The numbers on the color scales run from 200 to -200 for $(\mathrm{g}),(\mathrm{h}),(\mathrm{j})$, and (k), and from 400 to -400 for (i) and (l).

at $500 \mathrm{hPa}$ is fairly consistent between the model and the reanalysis data (cf. Figs. 4a and 4d). The climatological winter Aleutian low (Figs. 4c,f) is deepened and shifted eastward, while a dipole pattern with an anomalous high pressure region over Canada and an anomalous low pressure region over the southern United States is observed, reminiscent of the positive phase of the PacificNorth America (PNA) pattern (Horel and Wallace 1981; van Loon and Madden 1981). The low height anomalies over the North Pacific are somewhat extended in the zonal direction, and the high height anomalies over Canada are slightly shifted westward, in the model compared to the reanalysis. The El Niño teleconnection signal projects onto and amplifies the climatological stationary wave structure in the North Pacific. The intensification of the wave structure induced by El Niño is suggested to enhance the wave propagation into the stratosphere (Manzini et al. 2006; Garfinkel and Hartmann 2008). The stronger wave forcing in the stratosphere leads to a high geopotential height anomaly across the entire polar and Northern Pacific region (Figs. 4g,j), indicating a warming over the polar Northern Hemisphere stratosphere for El Niño winters as found in van Loon and Labitzke (1987) and Garfinkel and Hartmann (2008).

We also compare the El Niño response to the La Niña teleconnection pattern. For La Niña, the model prediction yields a pattern almost exactly opposite to $\mathrm{El}$ Niño (i.e., a negative phase of the PNA pattern). In the 
reanalysis data, however, the La Niña response does not have a clear linear relationship to the El Niño response (Zhang et al. 2014): the La Niña anomaly pattern shows a slightly different structure at $500 \mathrm{hPa}$, with a meridionally aligned dipole located around the Aleutian Islands. This pattern then also develops differently between the model and reanalysis with increasing height. While the model prediction at $10 \mathrm{hPa}$ shows a response that is opposite to El Niño with a low anomaly of geopotential height across the polar regions of the North Pacific, reanalysis shows a positive anomaly in the polar regions, with a negative anomaly south of that across the Aleutian islands. For the neutral ENSO phase, the composited anomalies are small and negligible, as expected (not shown).

Comparing the El Niño and La Niña anomaly patterns to the climatological stationary wave pattern (Figs. 4c,f), it becomes clear that a small change in the tropospheric wave anomaly structure may have a strong impact on how the anomaly projects onto the climatological stationary wave structure and therefore how the stratosphere reacts to the ENSO teleconnection. While the El Niño signal amplifies the climatological stationary wave structure in the North Pacific, the anomalies due to La Niña in the model ensemble mean have the opposite effect (i.e., a weakening of the wave structure). For the reanalysis, however, the La Niña signal is not opposite to the El Niño signal and it may in some cases even contribute to a deepening of the wave structure by amplifying the stationary wave pattern, as indicated by the differing pattern between the model and reanalysis in the La Niña composite within the stratosphere at $10 \mathrm{hPa}$.

This is also suggested by Garfinkel et al. (2012), who have identified key regions of influence in the North Pacific where extremely low geopotential height anomalies precede major SSWs. Small differences within these key regions may fundamentally alter the upward wave activity into the stratosphere in the model compared to the reanalysis data, and models generally tend to have problems reproducing the observed La Niña teleconnections (Garfinkel et al. 2012). While the observed teleconnections are based on a small sample size and may be subject to noise, the difference between the model and reanalysis in the La Niña anomalies may partly explain the difference between the model and reanalysis on the effect of La Niña on the extratropical stratosphere. For example, while Butler and Polvani (2011) find that in reanalysis, both La Niña and El Niño years show an increased number of SSW events, SSW events tend to be more frequent only during El Niño in models (Taguchi and Hartmann 2006; Garfinkel et al. 2012). In the present model prediction, El Niño years show a slightly increased number of SSWs with respect to La Niña years: El Niño years on average show a frequency of $0.63 \mathrm{SSW}$ events per winter, while La Niña years show an average of $0.46 \mathrm{SSW}$ events per winter, in comparison to $0.48 \mathrm{SSW}$ events for neutral winters (cp. Table 1).

Because of the difference in the teleconnection between the reanalysis and the model for La Niña events, and the suggested stronger impact of El Niño events on the stratosphere (Sassi 2004; Manzini et al. 2006; Garfinkel and Hartmann 2007), this study will focus on the predictability gained over the North Atlantic and Europe from El Niño events and their teleconnections.

As opposed to La Niña events, El Niño events show a clear teleconnection (Fig. 4) into the stratosphere through the North Pacific, which is consistent between the model prediction and the reanalysis.

\section{d. Stratospheric influence on the troposphere}

As established in the previous section, the teleconnections induced by El Niño events are associated with anomalies in the winter polar stratosphere (i.e., an anomalous increase in geopotential height and temperature). The positive temperature anomaly observed in the extratropical stratosphere during El Niño years exhibits a downward propagating signature in the winter evolution [Fig. 5; see also Fig. 4 in Manzini et al. (2006)]; that is, warm temperature anomalies during El Niño winters propagate downward into the troposphere. Temperature anomalies up to $7 \mathrm{~K}(5 \mathrm{~K})$ can be observed in the reanalysis (model). These anomalies are statistically significant according to a two-sample $t$ test comparing El Niño years against climatology. A cold anomaly can be observed in the lower stratosphere in early winter, which is replaced by the downward propagating warm anomaly in January-February. In the model, the warm anomaly structure is significant all the way to the surface, whereas in the reanalysis data the structure is only significant down to the upper troposphere. This is due to the much smaller sample size in the reanalysis (there are $10 \mathrm{El}$ Niño winters in the reanalysis as compared to $10 \mathrm{El}$ Niño winters represented by 9 ensemble members each; i.e., 90 samples in the model). The different sample size is also the reason for the smoother propagation signal in the model prediction as compared to reanalysis. The width of the significance level indicates the less robust response in the reanalysis data. The signal is slightly stronger in the reanalysis than in the model, as noted in Manzini et al. (2006) for an earlier version of the atmospheric model (MAECHAM5), as compared to ECHAM6 used here. However, the values in the reanalysis data are well contained within a standard deviation of the model data in all locations where either the model or the reanalysis shows a significant signal, except for being slightly above one standard deviation in the upper stratosphere in early 
a) model ensemble mean

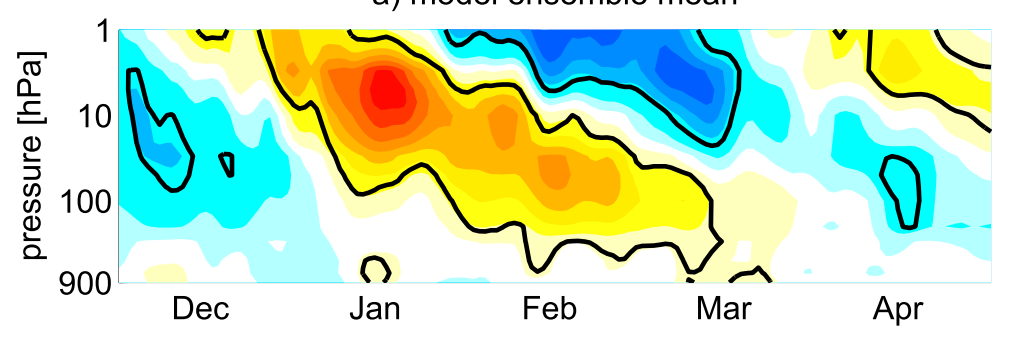

b) ERA-interim

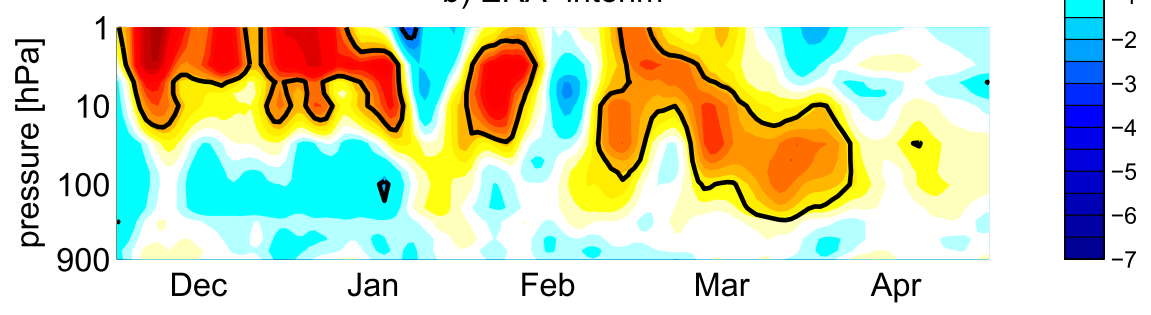

FIG. 5. Temperature anomalies (K) at $80^{\circ} \mathrm{N}$ averaged over all $10 \mathrm{El}$ Niño winters for (a) the model ensemble mean predictions and (b) ERA-Interim reanalysis data. The contour interval is $0.5 \mathrm{~K}$, and the zero contour has been omitted. The thick black line denotes the $99 \%$ confidence level according to a two-sample $t$ test comparing El Niño years against climatology.
December. The downward propagation is captured clearly in both the model and reanalysis.

The observed downward propagation of the temperature anomaly signal on the seasonal time scale is strongly reminiscent of the downward propagation observed for SSW events (Baldwin and Dunkerton 2001). It can be verified in the reanalysis data that for El Niño years with no SSW events in DJF, the temperature anomaly does not descend into the lower stratosphere before a SSW or final warming event occurs in MarchApril, whereas for years with SSW events during DJF, the temperature anomaly descends into the lower stratosphere during midwinter (not shown). However, there are only five cases in each category when subdividing the reanalysis data according to El Niño winters with and without SSW events.

Reanalysis data indicate that the downward propagation of the temperature anomalies on seasonal time scales is therefore likely induced by SSW events during winters with an anomalously warm polar cap. While El Niño induces a warm anomaly in the upper stratosphere, the impact on the troposphere is therefore likely to vanish if the anomalies do not reach the troposphere by means of SSW events. It can however be verified that winters with warm winter temperature anomalies in the upper stratosphere indeed correspond to winters with more SSW events (Fig. 6). While the definition of the threshold of SSW events may be arbitrary to a certain extent, Fig. 6 nevertheless confirms that the intuitive connection between warm stratospheric polar cap temperatures and an increased number of major stratospheric warming events holds for both in the model (gray circles) and the reanalysis (red circles). For the reanalysis data, the relationship holds with comparable values for the mean and standard deviation as for the

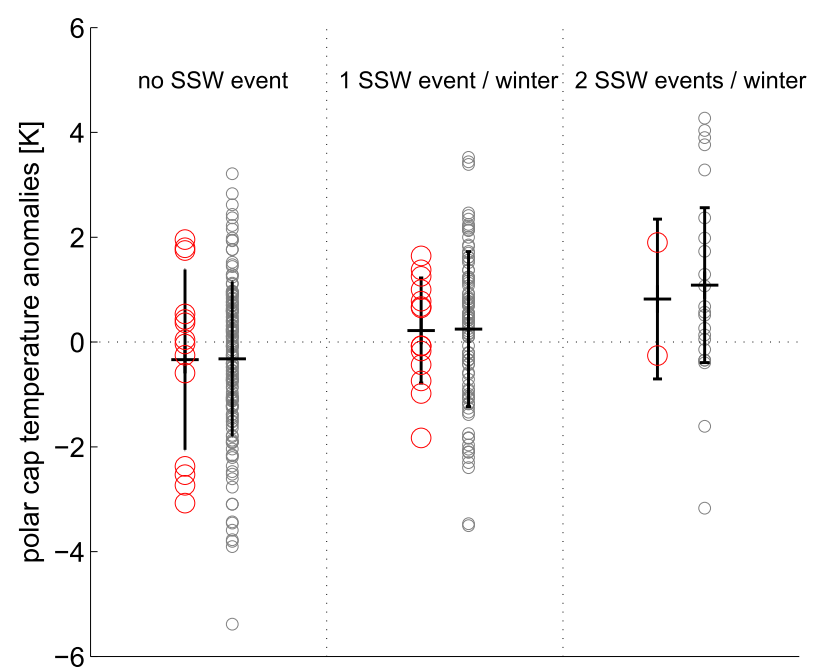

FIG. 6. Relationship between stratospheric polar cap temperature anomalies (defined as the temperature anomalies averaged over $60^{\circ}-90^{\circ} \mathrm{N}$ at $10 \mathrm{hPa}$ weighted by the square root of the cosine of latitude) and the number of sudden stratospheric warmings (for definition, see section 2) for DJF. Each winter (and ensemble member) is given by a separate circle: model ensemble members are depicted as small gray circles to the right of each category; ERA-Interim reanalysis is denoted by the larger red circles to the left. For a list of the SSW events in ERA-Interim, see Table 1. The black lines denote the mean and standard deviation for each category and dataset. 
model, although it is represented by a smaller number of events.

In summary, the stratospheric influence on the troposphere is dominantly exerted by SSW events, while El Niño winters show a higher number of SSW events and therefore tend to be more likely to show a stratospheric influence over Europe.

\section{e. Predictability over Europe}

While both El Niño and SSW events are suggested to influence the dominant weather pattern over Europe, it has been shown that the stratosphere is contemporaneously impacted by El Niño. Thus it is difficult to separate the influence of the El Niño teleconnection pathway that goes through the stratosphere and possible other (i.e., tropospheric) pathways. To estimate the contribution of the stratospheric pathway to the anomalous signal over Europe, Fig. 7 distinguishes between El Niño years when a strong stratospheric influence can be expected [i.e., when SSW events happen in midwinter (DJF)] and years when little stratospheric influence is expected (i.e., years with no major SSW events in DJF). For the model, all ensemble members have been examined separately for the occurrence of SSW events and composited accordingly. The composite 500-hPa geopotential height field response to SSW events is computed for the model (Fig. 7a) and the reanalysis (Fig. 7b) irrespective of the ENSO phase. The fields are averaged over the 2 months after the month during which a SSW event occurs in the stratosphere; for example, if an SSW event occurs anytime in December, the plot consists of an average over January and February. Both the model and the reanalysis show a negative NAO response after the composite SSW event, exhibiting the characteristic dipole anomaly pattern over the North Atlantic with a high geopotential height anomaly over Greenland and a negative anomaly over the southern Atlantic and central Europe, as expected from the observed response to SSW events (Baldwin and Dunkerton 2001). Again, the model response is smoother than the response in the reanalysis due to the larger sample size.

The geopotential height anomaly at $500 \mathrm{hPa}$ for the DJFM average of all El Niño years is then estimated in order to account for a possible lag in the surface response with respect to SSW events in DJF (Figs. 7c,d). For these years, model and reanalysis differ more, but in general they also show a tendency toward a negative NAO pattern with high geopotential height anomalies over eastern Canada and Greenland and a low geopotential height anomaly over the southeastern United States, extending across the Atlantic to Europe [compare the corresponding figures in Ineson and Scaife (2009) and Bell et al. (2009)]. The El Niño response in Figs. 7c and 7d shares similarities with the SSW response in Figs. 7a and 7b, both over the Atlantic and European region. Note, however, that the inter-event variability especially for El Niño is large, while it is smaller for SSW events.

To estimate the influence of El Niño through the stratospheric pathway, the El Niño winter response over Europe is examined for El Niño winters with (Figs. 7e,f) and without (Figs. 7g,h) SSW events [cf. the analysis in Butler et al. (2014)]. When including only winters during which a SSW event occurs (57 for the model, 5 for reanalysis), the pattern looks similar to the El Niño response, but in both the model and the reanalysis the anomalous geopotential heights extend farther across the Atlantic and into Europe. Essentially, the stratospheric pathway adds additional influence over the North Atlantic and Europe during El Niño winters (Ineson and Scaife 2009; Butler et al. 2014). However, the winter response over Europe for El Niño winters without SSW events (Figs. 7g,h), with 33 cases for the model and 5 cases for reanalysis, shows a completely different picture. In the reanalysis, the pattern no longer resembles a negative NAO pattern, although anomalies over North America still resemble a positive PNA-like pattern. In the model, the pattern also no longer resembles the negative NAO. While the model also exhibits a low anomaly over eastern Europe and a high anomaly off the coast of Spain, which was also found for surface pressure in Ineson and Scaife (2009), the model looks quite different from the reanalysis for winters with no SSW events. The very small sample size in the reanalysis and large inter-event variability might account for some of these differences. Nonetheless, it is clear that winters without a stratospheric pathway have a very different El Niño teleconnection over Europe than those that are influenced by the stratosphere, in agreement with previous studies (Ineson and Scaife 2009; Bell et al. 2009; Cagnazzo and Manzini 2009; Butler et al. 2014).

To assess how El Niño and SSW events may contribute to predictability over Europe, we now consider ACC maps for 500-hPa geopotential height for DJFM of all years (Fig. 8a) as compared to El Niño years only (Fig. 8c). Small improvements in predictability can be observed over northern Africa, northern Europe, and the western North Atlantic for El Niño years, but El Niño alone does not seem to significantly alter the predictability structure.

Two of the El Niño years that were used for the analysis were impacted by major volcanic eruptions (El Chichón in March-April 1982 and Mt. Pinatubo in June 1991, as indicated in Table 1). Volcanic forcing is included in the model to the extent that the initial conditions for November contain anomalies caused by volcanic emissions. Eruptions of tropical volcanoes generally tend 

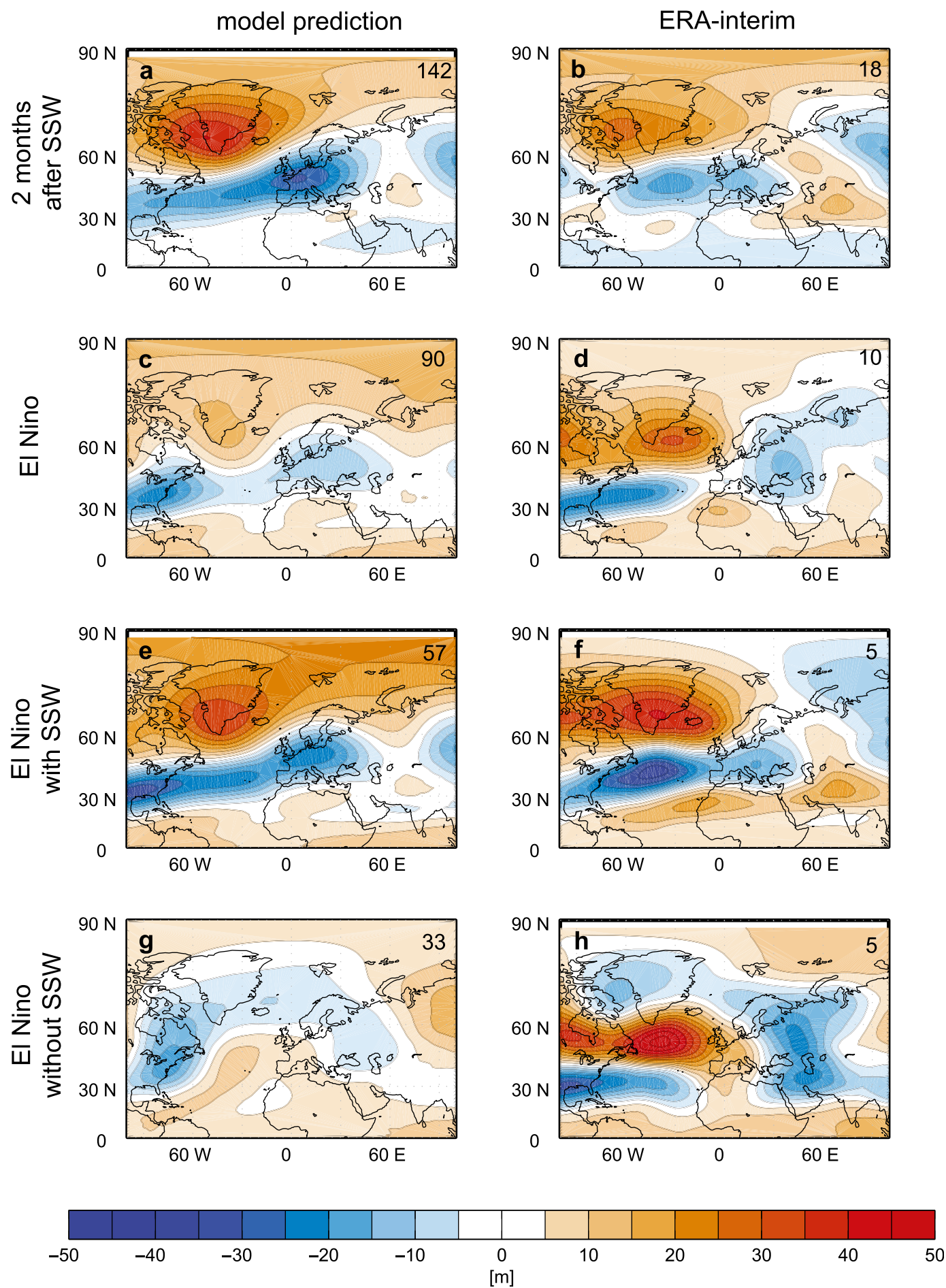

FIG. 7. The 500-hPa geopotential height anomaly (m) over the North Atlantic-Europe region averaged over (a),(b) the two months following the month within which a sudden warming occurred for all years, (c),(d) DJFM of El Niño years, (e),(f) DJFM of El Niño years during which a SSW occurs during DJF, and (g),(h) DJFM of El Niño years with no SSW event during DJF, for (left) the model ensemble mean prediction and (right) ERA-Interim reanalysis. The numbers in the top-right corners indicate the sample size available for each panel. Contour interval is $5 \mathrm{~m}$. 

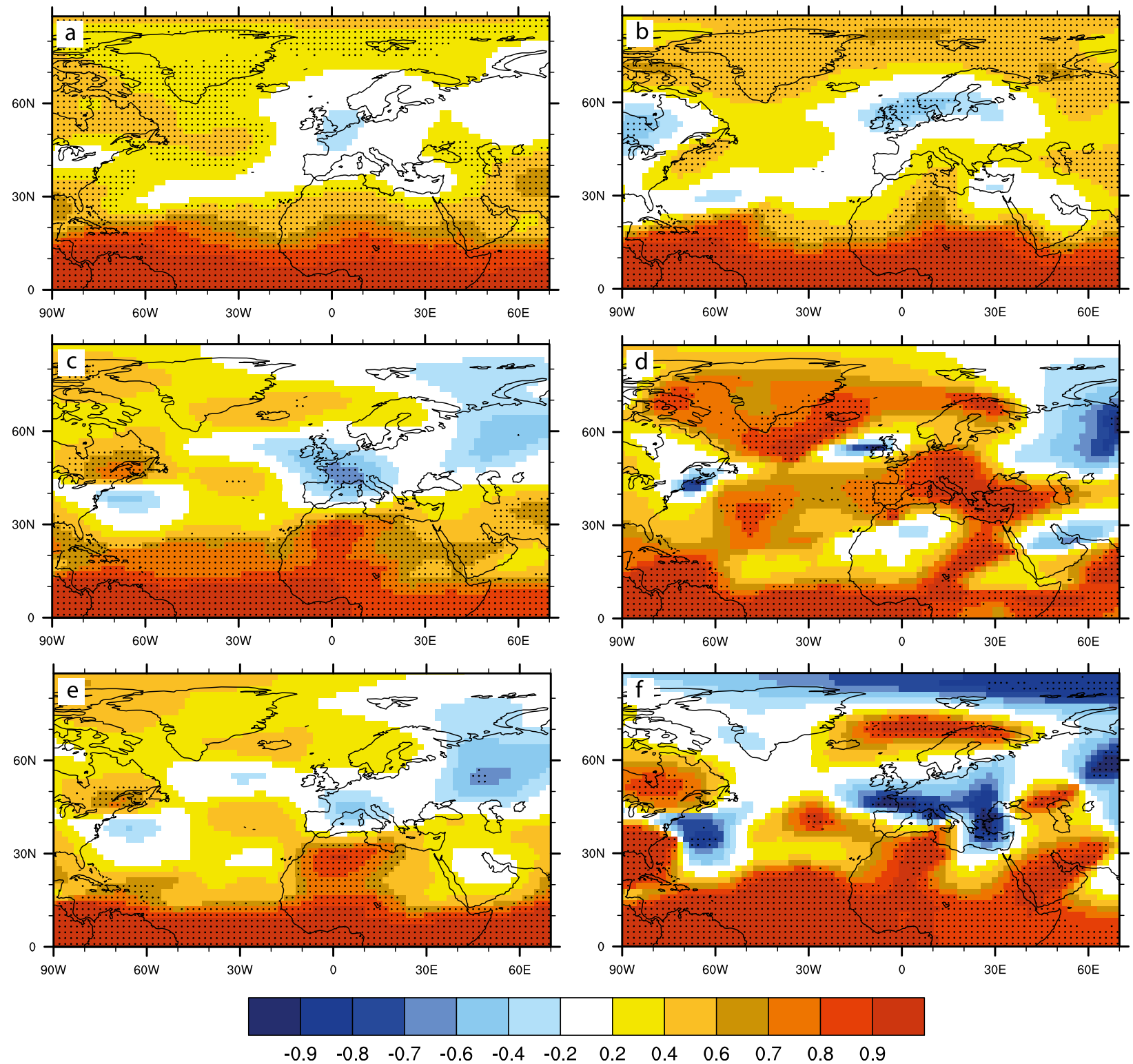

FIG. 8. Anomaly correlation coefficient for 500-hPa geopotential height for DJFM for (a) all $30 \mathrm{yr}$, (b) all years with SSW events (16 yr), (c) all El Niño years $(10 \mathrm{yr})$, (d) the El Niño years with at least one SSW event (5 yr), (e) the El Niño years with no volcanic influence (8 yr), and (f) the El Niño years without SSW events (5 yr). See Table 1 for the exact years used for this composite. Dots represent significant correlations at the $90 \%$ confidence level, calculated from 1000 bootstrap samples.

to cool the tropics on seasonal time scales (Robock and Mao 1995), including the tropical Atlantic, while El Niño tends to warm surface temperatures in the tropical Atlantic (van Loon and Madden 1981). The analysis has been repeated for the El Niño years without volcanoes (Fig. 8e). While the volcanic response over Europe may not be reliably reproduced in historical model runs of the MPI-ESM model as well as other models (Driscoll et al. 2012), for the two volcanic years considered here, extratropical predictability remains qualitativelyunchanged when removing the years with volcanic influence.
When assessing predictability arising from SSW events only (Fig. 8b), it is found that SSW events tend to significantly increase predictability over the polar regions. If, however, only SSW events during El Niño years are considered, predictability in addition improves considerably over central Europe. Note, however, that the signal only includes 5 years of data. For consistency, Fig. $8 \mathrm{f}$ shows predictability for the $5 \mathrm{El}$ Niño winters that do not exhibit a SSW event, and predictability is shown to considerably decrease over central Europe, as can be expected from the differing patterns between the model 
and reanalysis obtained for geopotential height at $500 \mathrm{hPa}$ for El Niño winters without SSW events (Fig. 7g,h).

\section{Discussion}

In summary, the presented results suggest that the observed response to El Niño over Europe is predominantly transferred by stratospheric variability. This is confirmed in both the model and reanalysis data, and it confirms earlier studies by Ineson and Scaife (2009), Cagnazzo et al. (2009), and Butler et al. (2014). It is also shown that predictability over Europe is increased when El Niño years coincide with SSW events.

A note of caution is that it has been suggested that different "flavors" of El Niño, namely the central Pacific (or Modoki) El Niño (CP El Niño; Trenberth and Smith 2006; Ashok et al. 2007) and the east Pacific El Niño (EP El Niño), may lead to different stratospheric teleconnections. The CP El Niño is characterized by maximum positive sea surface temperature anomalies in the central Pacific, in contrast to the EP El Niño, where the warm anomaly exhibits its maximum closer to the coast of South America. The present model setup typically shows more CP-type El Niños (cf. Fig. 2). While some studies find a strengthening of the stratospheric polar vortex (Hegyi and Deng 2011; Xie et al. 2012) for the CP El Niño in addition to an anomalous ridge in the North Pacific and a positive phase of the NAO (Hegyi and Deng 2011), Graf and Zanchettin (2012) and Zubiaurre and Calvo (2012) find the opposite response, although with a nonrobust impact on the stratospheric vortex (Zubiaurre and Calvo 2012). Garfinkel et al. (2013) show that the responses of the two types of El Niño are similar (i.e., a weakening of the polar vortex); while the contradictory results in other studies arise because of the different choice of definition for the CP and EP El Niño.

Apart from El Niño, another potential influence on the extratropical winter stratosphere is exerted through the quasi-biennial oscillation (QBO), which is suggested to affect the extratropics through the Holton-Tan effect (Holton and Tan 1980; Garfinkel and Hartmann 2007, 2010). However, since the present model resolution does not exhibit an internally generated QBO, the assimilated QBO in the present model runs is (at the considered lead times) degraded to a considerably weaker amplitude as compared to the observed QBO (Pohlmann et al. 2013), as expected from the missing processes that would maintain the QBO in the model. In addition, the Holton-Tan effect linking the QBO and the extratropical stratosphere in this model tends to be generally weak (Schmidt et al. 2013; Scaife et al. 2014). Since only 10 cases of El Niño are available to analyze in the present hindcasts, we have not further considered the influence of the QBO for the sake of better statistics. In a next step, model resolution could be increased to account for additional processes such as an internally generated QBO in order to improve the prediction, as shown in Pohlmann et al. (2013). It should, however, be mentioned that the seasonal prediction system employs a high-top version of the atmosphere. In previous studies low-top versions of the atmosphere have shown weaker and less persistent downward propagation of stratospheric anomalies, which may partially reflect the much weaker stratospheric variability in these models (Hardiman et al. 2012; Charlton-Perez et al. 2013).

Other precursors to SSW events include persistent, strong tropospheric events such as blocking (Martius et al. 2009). Recently, it has been shown that blocking events are modulated by tropical Pacific anomalies in the form of ENSO, and that El Niño and La Niña tend to have different preferred blocking locations, while both phases of ENSO increase blocking persistence in reanalysis data (Barriopedro and Calvo 2014). This finding emphasizes and further differentiates the finding of an increased frequency of SSW events during both El Niño and La Niña (Butler and Polvani 2011). For the El Niño phase discussed in this study, more persistent blocking signals in the North Pacific likely contribute to the pathway through the stratosphere during El Niño years, possibly by channeling the wave flux into the stratosphere. A detailed study of the blocking is, however, beyond the scope of this study, and the reader is referred to Barriopedro and Calvo (2014) for the dynamical connection between these phenomena.

The present analysis is constrained to El Niño as the La Niña teleconnections are not well represented in the model as compared to reanalysis. This presents an additional challenge to the modeling community, since models generally overestimate the linearity of the ENSO teleconnection (Garfinkel et al. 2012). The impact of La Niña on the extratropical stratosphere will have to be examined in more detail in both model and reanalysis studies to better understand the stratospheric pathway and its impact during La Niña.

Finally, the results are limited by the small sample size of available El Niño winters, which then have to be further subdivided by the occurrence versus nonoccurrence of SSW events, since these turn out to add a significant amount of predictability over Europe. Since in models it is not possible to predict specific observed SSW events at the considered lead times, which exceed predictability time scales for the stratosphere, the ensemble members have to be separated into those that contain SSW events and those that do not. While this considerably limits the data - as can be seen from Fig. 8, where the significance levels indicate that only areas of large ACC are significant for the panels where only five cases are included-the 
significance test nevertheless shows that predictability is significantly improved for El Niño years with SSW events.

A way around the problem of not predicting specific SSW events will be to initialize a seasonal prediction ensemble within the predictive range of a SSW event (e.g., at the onset of an event), as done in Sigmond et al. (2013), among others. The results of the present study indicate that predictability will most likely be increased for these experiments, and the operational use of seasonal prediction models, which are currently initialized once a month, will make it possible to gain predictability from $\mathrm{El} \mathrm{Niño} \mathrm{and}$ SSW events based on the results found in this study.

\section{Summary and conclusions}

The performance of the MPI-ESM seasonal prediction system is assessed with respect to observed ENSO teleconnections. In particular, predictability over the North Atlantic-Europe region is analyzed for El Niño and its stratospheric teleconnection pathway.

The evolution of El Niño events can be reliably predicted in the MPI-ESM seasonal prediction system for up to 6 months, and the model predictions show a connection between the El Niño region, the North Pacific and the stratosphere during El Niño years (i.e., the North Pacific Aleutian low tends to deepen and the extratropical northern stratosphere tends to warm during El Niño years). While specific stratospheric sudden warming events cannot be predicted by the model at lead times longer than 2 weeks, the mean state of the tropical Pacific gives a tendency of the mean temperature anomaly and the number of sudden warmings to expect for a given winter. The stratospheric warm anomaly can then be shown to descend through the stratosphere on seasonal time scales, showing a significant response in the Northern Hemisphere troposphere.

Similar anomaly patterns in $500-\mathrm{hPa}$ geopotential height (i.e., a negative NAO response) arise for El Niño and SSW events. This anomaly over Europe can be shown to emerge much more strongly when SSW events occur in the stratosphere during an El Niño winter, indicating that the stratospheric pathway is crucial for the remote response of El Niño over Europe. Predictability over Europe is then shown to be increased during El Niño years that exhibit SSW events.

While teleconnections in the model are generally weak (e.g., the Holton-Tan effect) and anomalies and teleconnections forced by La Niña are not well represented in the model, the seasonal forecasting efforts shown here represent the first steps toward examining the representation of the El Niño teleconnection pathway through the stratosphere on seasonal time scales.
Several studies (e.g., Ineson and Scaife 2009; Cagnazzo et al. 2009; Butler et al. 2014) have suggested that the stratospheric pathway is important for inducing largescale weather patterns such as the NAO. This study confirms these results by showing that the pattern obtained by compositing El Niño events is only valid for a stratospheric influence. Predictability over Europe is indeed increased by separating the stratospheric pathway and by using both stratospheric sudden warmings and El Niño as predictors in a seasonal forecasting model. It is therefore necessary to represent both processes accordingly in seasonal prediction systems. The present study confirms earlier studies and indicates that the stratospheric pathway is indeed key to predictability over Europe, in terms of the occurrence of SSW events being crucial to obtaining the expected negative NAO signal over Europe that is observed for El Niño events. These results promise to considerably increase predictability over Europe during El Niño years with strong stratospheric variability.

Acknowledgments. We thank Elisa Manzini, Shigeo Yoden, Masakazu Taguchi, and Thomas Reichler for helpful discussions of the presented results, Modali Kameswarrao and Martin Scharffenberg for technical support, Tim Stockdale for consultation on the computation of the statistics, and Felix Bunzel for helpful discussions of the model setup. This work was partly supported through the Cluster of Excellence CliSAP (EXC177), Universität Hamburg, funded through the German Research Foundation (DFG) (DD, JB). Further, research leading to these results has received funding from the European Union's Seventh Framework Programme (FP7/2007-2013) under Grant Agreement 308378 ENV.2012.6.1-1: Seasonal-to-decadal climate predictions towards climate services (http://www.specs-fp7. $\mathrm{eu} /$ ). The work of MB was supported by the Federal Ministry for Education and Research in Germany (BMBF) through the research program MiKlip (FKZ:01LP1130A).

\section{REFERENCES}

Arribas, A., and Coauthors, 2011: The GloSea4 ensemble prediction system for seasonal forecasting. Mon. Wea. Rev., 139, 1891-1910, doi:10.1175/2010MWR3615.1.

Ashok, K., S. K. Behera, S. A. Rao, H. Weng, and T. Yamagata, 2007: El Niño Modoki and its possible teleconnection. J. Geophys. Res., 112, C11007, doi:10.1029/2006JC003798.

Baehr, J., and R. Piontek, 2014: Ensemble initialization of the oceanic component of a coupled model through bred vectors at seasonal-to-interannual time scales. Geosci. Model Dev., 7, 453-461, doi:10.5194/gmd-7-453-2014.

, and Coauthors, 2014: The prediction of surface temperature in the new seasonal prediction system based on the MPI-ESM coupled climate model. Climate Dyn., doi:10.1007/ s00382-014-2399-7, in press. 
Baldwin, M., and T. Dunkerton, 2001: Stratospheric harbingers of anomalous weather regimes. Science, 294, 581-584, doi:10.1126/ science.1063315.

Balmaseda, M. A., K. Mogensen, and A. T. Weaver, 2013: Evaluation of the ECMWF Ocean Reanalysis System ORAS4. Quart. J. Roy. Meteor. Soc., 139, 1132-1161, doi:10.1002/ qj.2063.

Barriopedro, D., and N. Calvo, 2014: On the relationship between ENSO, stratospheric sudden warmings, and blocking. J. Climate, 27, 4704-4720, doi:10.1175/JCLI-D-13-00770.1.

Bell, C. J., L. J. Gray, A. J. Charlton-Perez, M. M. Joshi, and A. A. Scaife, 2009: Stratospheric communication of El Niño teleconnections to European winter. J. Climate, 22, 4083-4096, doi:10.1175/2009JCLI2717.1.

Brönnimann, S., 2007: Impact of El Niño-Southern Oscillation on European climate. Rev. Geophys., 45, RG3003, doi:10.1029/ 2006RG000199.

Butler, A. H., and L. M. Polvani, 2011: El Niño, La Niña, and stratospheric sudden warmings: A reevaluation in light of the observational record. Geophys. Res. Lett., 38, L13807, doi:10.1029/ 2011 GL048084.

,$- \ldots$, and C. Deser, 2014: Separating the stratospheric and tropospheric pathways of El Niño-Southern Oscillation teleconnections. Environ. Res. Lett., 9, 024014, doi:10.1088/1748-9326/ 9/2/024014.

Cagnazzo, C., and E. Manzini, 2009: Impact of the stratosphere on the winter tropospheric teleconnections between ENSO and the North Atlantic and European region. J. Climate, 22, 1223 1238, doi:10.1175/2008JCLI2549.1.

_ perature and ozone responses to ENSO inferred from an ensemble of chemistry climate models. Atmos. Chem. Phys., 9, 8935-8948, doi:10.5194/acp-9-8935-2009.

Charlton, A. J., and L. M. Polvani, 2007: A new look at stratospheric sudden warmings. Part I: Climatology and modeling benchmarks. J. Climate, 20, 449-469, doi:10.1175/JCLI3996.1.

Charlton-Perez, A. J., and Coauthors, 2013: On the lack of stratospheric dynamical variability in low-top versions of the CMIP5 models. J. Geophys. Res. Atmos., 118, 2494-2505, doi:10.1002/jgrd.50125.

Dee, D. P., and Coauthors, 2011: The ERA-Interim reanalysis: Configuration and performance of the data assimilation system. Quart. J. Roy. Meteor. Soc., 137, 553-597, doi:10.1002/ qj.828.

Driscoll, S., A. Bozzo, L. J. Gray, A. Robock, and G. Stenchikov, 2012: Coupled Model Intercomparison Project 5 (CMIP5) simulations of climate following volcanic eruptions. J. Geophys. Res., 117, D17105, doi:10.1029/2012JD017607.

Fetterer, F., K. Knowles, W. Meier, and M. Savoie, 2002: Sea ice index. National Snow and Ice Data Center, doi:10.7265/ N5QJ7F7W.

Fletcher, C. G., and P. J. Kushner, 2011: The role of linear interference in the annular mode response to tropical SST forcing. J. Climate, 24, 778-794, doi:10.1175/2010JCLI3735.1.

Fraedrich, K., and K. Müller, 1992: Climate anomalies in Europe associated with ENSO extremes. Int. J. Climatol., 12, 25-31, doi:10.1002/joc.3370120104.

Free, M., and D. J. Seidel, 2009: Observed El Niño-Southern Oscillation temperature signal in the stratosphere. J. Geophys. Res., 114, D23108, doi:10.1029/2009JD012420.

García-Herrera, R., N. Calvo, R. R. Garcia, and M. A. Giorgetta, 2006: Propagation of ENSO temperature signals into the middle atmosphere: A comparison of two general circulation models and ERA-40 reanalysis data. J. Geophys. Res., 111, D06101, doi:10.1029/2005JD006061.

Garfinkel, C. I., and D. L. Hartmann, 2007: Effects of the El NiñoSouthern Oscillation and the quasi-biennial oscillation on polar temperatures in the stratosphere. J. Geophys. Res., 112, D19112, doi:10.1029/2007JD008481.

— , and - 2008: Different ENSO teleconnections and their effects on the stratospheric polar vortex. J. Geophys. Res., 113, D18114, doi:10.1029/2008JD009920.

$\longrightarrow$, and - 2010: Influence of the quasi-biennial oscillation on the North Pacific and El Niño teleconnections. J. Geophys. Res., 115, D20116, doi:10.1029/2010JD014181.

—, A. H. Butler, D. W. Waugh, M. M. Hurwitz, and L. M. Polvani, 2012: Why might stratospheric sudden warmings occur with similar frequency in El Niño and La Niña winters? J. Geophys. Res., 117, D19106, doi:10.1029/2012JD017777.

— M. M. Hurwitz, D. W. Waugh, and A. H. Butler, 2013: Are the teleconnections of central Pacific and eastern Pacific El Niño distinct in boreal wintertime? Climate Dyn., 41, 18351852, doi:10.1007/s00382-012-1570-2.

Gerber, E. P., C. Orbe, and L. M. Polvani, 2009: Stratospheric influence on the tropospheric circulation revealed by idealized ensemble forecasts. Geophys. Res. Lett., 36, L24801, doi:10.1029/ 2009GL040913.

Graf, H.-F., and D. Zanchettin, 2012: Central Pacific El Niño, the subtropical bridge, and Eurasian climate. J. Geophys. Res., 117, D01102, doi:10.1029/2011JD016493.

Hardiman, S. C., N. Butchart, T. J. Hinton, S. M. Osprey, and L. J. Gray, 2012: The effect of a well-resolved stratosphere on surface climate: Differences between CMIP5 simulations with high and low top versions of the Met Office climate model. J. Climate, 25, 7083-7099, doi:10.1175/JCLI-D-11-00579.1.

Hegyi, B. M., and Y. Deng, 2011: A dynamical fingerprint of tropical Pacific sea surface temperatures on the decadal-scale variability of cool-season Arctic precipitation. J. Geophys. Res., 116, D20121, doi:10.1029/2011JD016001.

Hitchcock, P., T. G. Shepherd, M. Taguchi, S. Yoden, and S. Noguchi, 2013: Lower-stratospheric radiative damping and polar-night jet oscillation events. J. Atmos. Sci., 70, 1391-1408, doi:10.1175/ JAS-D-12-0193.1.

Holton, J. R., and H. C. Tan, 1980: The influence of the equatorial quasi-biennial oscillation on the global circulation at $50 \mathrm{mb}$. J. Atmos. Sci., 37, 2200-2208, doi:10.1175/1520-0469(1980)037<2200: TIOTEQ $>2.0 . \mathrm{CO} ; 2$.

Horel, J. D., and J. M. Wallace, 1981: Planetary-scale atmospheric phenomena associated with the Southern Oscillation. Mon. Wea. Rev., 109, 813-829, doi:10.1175/1520-0493(1981)109<0813: PSAPAW $>2.0 . \mathrm{CO} ; 2$.

Ineson, S., and A. Scaife, 2009: The role of the stratosphere in the European climate response to El Niño. Nat. Geosci., 2, 32-36, doi:10.1038/ngeo381.

Jungclaus, J., and Coauthors, 2013: Characteristics of the ocean simulations in the Max Planck Institute Ocean Model (MPIOM), the ocean component of the MPI-Earth system model. J. Adv. Model. Earth Syst., 5, 422-446, doi:10.1002/jame.20023.

Li, Y., and N.-C. Lau, 2013: Influences of ENSO on stratospheric variability, and the descent of stratospheric perturbations into the lower troposphere. J. Climate, 26, 4725-4748, doi:10.1175/ JCLI-D-12-00581.1.

Luo, J.-J., S. Masson, E. Roeckner, G. Madec, and T. Yamagata, 2005: Reducing climatology bias in an ocean-atmosphere CGCM with improved coupling physics. J. Climate, 18, 2344 2360, doi:10.1175/JCLI3404.1. 
Manzini, E., M. A. Giorgetta, M. Esch, L. Kornblueh, and E. Roeckner, 2006: The influence of sea surface temperatures on the northern winter stratosphere: Ensemble simulations with the MAECHAM5 model. J. Climate, 19, 3863-3881, doi:10.1175/JCLI3826.1.

Marshall, A., and A. A. Scaife, 2010: Improved predictability of stratospheric sudden warming events in an atmospheric general circulation model with enhanced stratospheric resolution. J. Geophys. Res., 115, D16114, doi:10.1029/2009JD012643.

Martius, O., L. M. Polvani, and H. Davies, 2009: Blocking precursors to stratospheric sudden warming events. Geophys. Res. Lett., 36, L14806, doi:10.1029/2009GL038776.

Mukougawa, H., T. Hirooka, and Y. Kuroda, 2009: Influence of stratospheric circulation on the predictability of the tropospheric northern annular mode. Geophys. Res. Lett., 36, L08814, doi:10.1029/2008GL037127.

Pohlmann, H., and Coauthors, 2013: Improved forecast skill in the tropics in the new MiKlip decadal climate predictions. Geophys. Res. Lett., 40, 5798-5802, doi:10.1002/2013GL058051.

Polvani, L. M., and D. Waugh, 2004: Upward wave activity flux as a precursor to extreme stratospheric events and subsequent anomalous surface weather regimes. J. Climate, 17, 3548-3554, doi:10.1175/1520-0442(2004)017<3548:UWAFAA > 2.0.CO;2.

Quiroz, R. S., 1983: The climate of the "El Niño" winter of 1982 83-A season of extraordinary climatic anomalies. Mon. Wea. Rev., 111, 1685-1706, doi:10.1175/1520-0493(1983)111<1685: TCOTNW $>2.0 . \mathrm{CO} ; 2$.

Robock, A., and J. Mao, 1995: The volcanic signal in surface temperature observations. J. Climate, 8, 1086-1103, doi:10.1175/ 1520-0442(1995)008<1086:TVSIST > 2.0.CO;2.

Sassi, F., 2004: Effect of El Niño-Southern Oscillation on the dynamical, thermal, and chemical structure of the middle atmosphere. J. Geophys. Res., 109, D17108, doi:10.1029/ 2003JD004434.

Scaife, A. A., and I. N. James, 2000: Response of the stratosphere to interannual variability of tropospheric planetary waves. Quart. J. Roy. Meteor. Soc., 126, 275-297, doi:10.1002/qj.49712656214. - and J. R. Knight, 2008: Ensemble simulations of the cold European winter of 2005-2006. Quart. J. Roy. Meteor. Soc., 134, 1647-1659, doi:10.1002/qj.312.

_ - and Coauthors, 2014: Predictability of the quasi-biennial oscillation and its northern winter teleconnection on seasonal to decadal timescales. Geophys. Res. Lett., 41, 1752-1758, doi:10.1002/2013GL059160.

Schmidt, H., and Coauthors, 2013: Response of the middle atmosphere to anthropogenic and natural forcings in the CMIP5 simulations with the Max Planck Institute Earth System Model. J. Adv. Model. Earth Syst., 5, 98-116, doi:10.1002/jame.20014.

Sigmond, M., J. F. Scinocca, V. V. Kharin, and T. G. Shepherd, 2013: Enhanced seasonal forecast skill following stratospheric sudden warmings. Nat. Geosci., 6, 98-102, doi:10.1038/ngeo1698.

Smith, K. L., C. G. Fletcher, and P. J. Kushner, 2010: The role of linear interference in the annular mode response to extratropical surface forcing. J. Climate, 23, 6036-6050, doi:10.1175/ 2010JCLI3606.1.

Stevens, B., and Coauthors, 2013: The atmospheric component of the MPI-M Earth System Model: ECHAM6. J. Adv. Model. Earth Syst., 5, 146-172, doi:10.1002/jame.20015.

Taguchi, M., and D. L. Hartmann, 2006: Increased occurrence of stratospheric sudden warmings during El Niño as simulated by WACCM. J. Climate, 19, 324-332, doi:10.1175/JCLI3655.1.

Taylor, K. E., R. J. Stouffer, and G. A. Meehl, 2012: An overview of CMIP5 and the experiment design. Bull. Amer. Meteor. Soc., 93, 485-498, doi:10.1175/BAMS-D-11-00094.1.

Thompson, D., M. Baldwin, and J. Wallace, 2002: Stratospheric connection to Northern Hemisphere wintertime weather: Implications for prediction. J. Climate, 15, 1421-1428, doi:10.1175/ 1520-0442(2002)015<1421:SCTNHW >2.0.CO;2.

Tietsche, S., D. Notz, J. H. Jungclaus, and J. Marotzke, 2013: Assimilation of sea-ice concentration in a global climate modelPhysical and statistical aspects. Ocean Sci., 9, 19-36, doi:10.5194/os-9-19-2013.

Toniazzo, T., and A. A. Scaife, 2006: The influence of ENSO on winter North Atlantic climate. Geophys. Res. Lett., 33, L24704, doi:10.1029/2006GL027881.

Trenberth, K. E., and L. Smith, 2006: The vertical structure of temperature in the tropics: Different flavors of El Niño. J. Climate, 19, 4956-4973.

—, G. W. Branstator, D. Karoly, A. Kumar, N.-C. Lau, and C. Ropelewski, 1998: Progress during TOGA in understanding and modeling global teleconnections associated with tropical sea surface temperatures. J. Geophys. Res., 103, 14291-14324, doi:10.1029/97JC01444.

Uppala, S. M., and Coauthors, 2005: The ERA-40 Re-Analysis. Quart. J. Roy. Meteor. Soc., 131, 2961-3012, doi:10.1256/ qj.04.176.

van Loon, H., and R. A. Madden, 1981: The Southern Oscillation. Part I: Global associations with pressure and temperature in northern winter. Mon. Wea. Rev., 109, 1150-1162, doi:10.1175/ 1520-0493(1981)109<1150:TSOPIG > 2.0.CO;2.

_ , and K. Labitzke, 1987: The Southern Oscillation. Part V: The anomalies in the lower stratosphere of the Northern Hemisphere in winter and a comparison with the quasi-biennial oscillation. Mon. Wea. Rev., 115, 357-369, doi:10.1175/ 1520-0493(1987)115<0357:TSOPVT >2.0.CO;2.

Xie, F., J. P. Li, W. S. Tian, J. Feng, and Y. Huo, 2012: Signals of El Niño Modoki in the tropical tropopause layer and stratosphere. Atmos. Chem. Phys., 12, 5259-5273, doi:10.5194/ acp-12-5259-2012.

Zhang, T., J. Perlwitz, and M. P. Hoerling, 2014: What is responsible for the strong observed asymmetry in teleconnections between El Niño and La Niña? Geophys. Res. Lett., 41, 10191025, doi:10.1002/2013GL058964.

Zubiaurre, I., and N. Calvo, 2012: The El Niño-Southern Oscillation (ENSO) Modoki signal in the stratosphere. J. Geophys. Res., 117, D04104, doi:10.1029/2011JD016690. 